\title{
PERANCANGAN PONDOK PESANTREN MODERN UMMUL QURO DI KABUPATEN BOGOR
}

\author{
Sundana $^{1}$, Ratu Arum Kusumawardhani ${ }^{2}$, Ryan Hidayat ${ }^{3}$ \\ ${ }^{1}$ Universitas Indraprasta PGRI, Program Studi Arsitektur \\ soendana@gmail.com \\ ${ }^{2}$ Universitas Indraprasta PGRI, Program Studi Arsitektur \\ arum_q@yahoo.com \\ ${ }^{3}$ Universitas Indraprasta PGRI, Program Studi Arsitektur \\ ryansastra3@gmail.com
}

\begin{abstract}
AUmmul Qoro Modern Islamic boarding school is education institution established since 1993. Ummul Quro organize education program for Islamic junior high school and Islamic high school for boy and girl, currently the students has amount 4000 children. Along the public trust to choose Islamic boarding school as facilities for their children has impact increasingly the number of students significantly and caused the capacity of school is insufficient. This issue as a background to Design Ummul Quro Modern Islamic boarding School in Bogor to build new Islamic boarding school for girl separately in new location. Establishment Islamic boarding school for girl students for Islamic junior high school and Islamic high school in the new site is an effort to increase of Ummul Quro Modern Islamic boarding school to graduate more students as a successor generation of Nation which have character smart, independent, nobel character based on faith and godly to Allah SWT, The implementation of architectural theory in design of Islamic boarding school by calculating space base on requirement with a proper zoning and dynamic circulation, open and simple in design and functionally appropriate is the concept of design to make the boarding school comfortable for students, teachers, visitors and to facilitating and supporting boarding school programs effectively and efficiently.
\end{abstract}

Key Words: Boarding School, Modern, Ummul Quro, Bogor

\begin{abstract}
Abstrak : Pondok Pesantren Modern Ummul Quro merupakan lembaga pendidikan Islam yang telah berdiri sejak tahun 1993. Ummul Quro menyelenggarakan program pendidikan untuk jenjang Madrasah Tsanawiyah (setingkat SLTP) dan Mandrasah Alliyah (setingkat SLTA) baik putra maupun putri, yang saat ini jumlah peserta didik mencapai 4000 santri dan santriwati. Seiring kepercayaan masyarakat dalam memilih pesantren sebagai sarana pendidikan bagi putra dan putri nya menyebabkan pertumbuhan jumlah santri yang sangat signifikan sehingga kapasitas sudah tidak mencukupi. Hal ini melatarbelakangi perancangan pondok pesantren modern ummul quro di kabupaten bogor dengan cara mendirikan pondok pesantren khusus putri di lokasi baru. Pembangunan pondok pesantren putri untuk tingkat Tsanawiyah (SLTP) dan Alliyah (SMA) dilokasi yang baru merupakan salah satu upaya Pesantren Ummul Quro Al-Islami dalam rangka meningkatkan peran pondok pesantren agar dapat lebih banyak melahirkan santri-santri sebagai generasi penerus Bangsa yang cerdas, mandiri, berakhlak mulia dengan berlandaskan keimanan dan ketaqwaan kepada Allah SWT. Penerapan kaidah-kaidah arsitektur dalam perancangan pondok pesantren berdasarkan perhitungan kebutuhan ruang dengan zonasi yang tepat dan sirkulasi yang dinamis, terbuka dan sederhana secara desain serta sesuai secara fungsi merupakan konsep dari perancangan sehingga menjadikan pondok pesantren yang nyaman bagi santri, guru, pengunjung dan sebagai sarana penunjang program-program pesantren secara efektif dan efisien.

Kata Kunci : pondok, pesantren, Modern, Ummul Quro, Bogor
\end{abstract}

\section{PENDAHULUAN}

Pendahuluan Pendidikan merupakan salah satu aspek yang sangat penting seperti yang tercantum dalam Undang-undang Dasar 1945 pasal 31 yang merupakan kewajiban Negara untuk kemajuan Bangsa. Dalam hal ini setiap elemen masyarakat khususnya umat Islam memiliki tanggung jawab yang sama dalam hal pendidikan untuk ikut serta dalam pembangunan dalam rangka mewujudkan generasi penerus Bangsa yang beriman dan berakhlak mulia serta bertakwa kepada Allah SWT.

Sebagai bukti pentingnya pendidikan bagi masyarakat, pemerintah Republik Indonesia mencanangkannya pendidikan wajib yang tertuang dalam Undang-undang No.20 Tahun 2003 Bab VIII Pasal 34 dan di atur lebih lanjut dengan Peraturan Pemerintah No 47 Tahun 2008. 
Pesantren merupakan produk budaya masyarakat Indonesia yang berawal dari kesadaran akan pentingnya arti sebuah pendidikan bagi orang pribumi yang tumbuh secara alami yang sesuai dengan pandangan para ahli "Pesantren sebagai "institusi budaya" lahir atas prakarsa dan inisiatif masyarakat" Moh. Ali Aziz (2005:207).

Pondok Pesantren Ummul Quro merupakan lembaga pendidikan yang menyelenggarakan program pendidikan tingkan Madrasah Tsanawiyah (setingkat SLTP) dan Madrasah Alliyah (setingkat SLTA) bagi putra dan putri. untuk dapat masuk ke Pondok pesantren Ummul Quro calon peserta didik lulusan Sekolah Dasar (SD) atau Madrasah Ibtidaiyah (MI), harus melakukan pendaftaran serta melalui tes yaitu : pengetahuan umum, tes baca tulis Al-Qur'an dan tes kesehatan. Untuk tes baca tulis Al-Qur'an nilai minimum kelulusan adalah 70. Bagi calon peserta yang mendapatkan nilai di bawah 70, diwajibkan mengikuti program pendidikan Pra-Pesantren selama 30 hari untuk mempelajari Baca dan tulis Al-Qur'an.

Pembangunan pondok pesantren putri untuk tingkat Tsanawiyah (SLTP) dan Alliyah (SMA) dilokasi yang baru merupakan salah satu upaya Pesantren Ummul Quro Al-Islami dalam rangka meningkatkan peran pondok pesantren sehingga agar dapat lebih banyak melahirkan santri-santri sebagai generasi penerus Bangsa yang cerdas, mandiri, berakhlak mulia dengan berlandaskan keimanan dan ketaqwaan kepada Allah SWT.

Peningkatan fasilitas secara fisik dan perencanaan yang sistematis dalam penaataan ruang belajar, kamar istirahat santri dan guru, dan sarana pendukung lainnya yang lebih efektif dan efisien berdasarkan kaidah-kaidah arsitektur yang lebih terbuka dan sederhana secara desain serta sesuai secara fungsi serta sirkulasi yang dinamis merupakan konsep dalam perancangan untuk kebutuhan pesantren yang mendukung terlaksananya program-program kegiatan pendidikan yang dilaksanakan dalam pondok pesantren secara optimal dan menciptakan lingkungan yang harmonis sehingga kenyamanan akan tercipta khususnya bagi para santri, guru dan pengunjung dalam setiap kegiatan.

\section{METODOLOGI}

Metode pendekatan rancangan penyusun mengkombinasikan dengan hal-hal yang telah dirumuskan oleh Ikatan Arsitek Indonesia dalam pekerjaan perencanaan dan perancangan Arsitektur akan dilaksanakan dalam tahapan pekerjaan sebagai berikut (Lingkup Pekerjaan Seorang Arsitek, dalam Ikatan Arsitek Indonesia atau IAI):

Tahap Pertama yaitu Konsep Rancangan Arsitektur. Sebelum kegiatan perencangan dimulai, perlu ada kejelasan mengenai semua data dan informasi dari pengguna yang terkait tentang kebutuhan dan persyaratan pembangunan agar maksud dan tujuan pembangunan dapat terpenuhi dengan baik.

Tahap ke-dua Penulis akan melakukan persiapan perancangan yang meliputi pemeriksaan seluruh data serta informasi yang diterima, membuat analisis dan pengelola data yang menghasilkan:

Program rancangan yang disusun oleh Penulis berdasarkan pengelola data primer maupun sekunder serta informasi lain untuk mencapai batasan tujuan proyek serta kendala persyaratan/ ketentuan pembangunan yang berlaku. Setelah program rancangan diperiksa dan mendapat persetujuan dari dosen pembimbing teknik, selanjutnya digunakan sebagai dasar untuk dasar rancangan.

Berdasarkan konsep rancangan yang merupakan dasar pemikiran dan pertimbangan-pertimbangan semua bidang terkait (baik struktur, mekanikal, elektrikal, dan atau bidang keahlian lain bila diperlukan) yang melandasi perwujudan gagasan rancangan yang menampung semua aspek, kebutuhan.ini menjelaskan jenis metode (kualitatif, kuantitatif atau mixed-method) disertai rincian metode pengumpulan data dan metode analisis data yang digunakan. Bagian ini juga dapat menjelaskan perspektif yang mendasari pemilihan metode tersebut.

\section{WAKTU}

Tabel 1 Waktu Perancangan

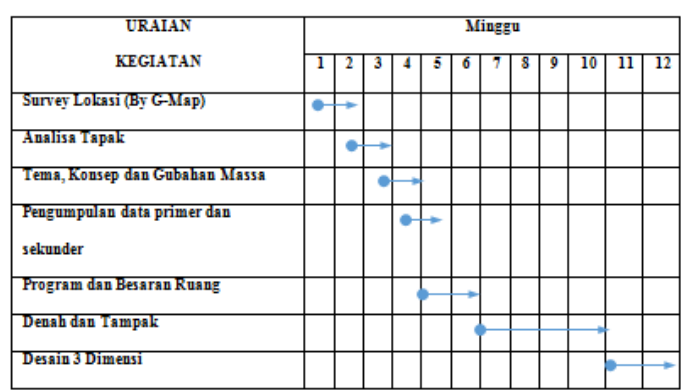




\section{HASIL DAN PEMBAHASAN}

Lokasi Tapak

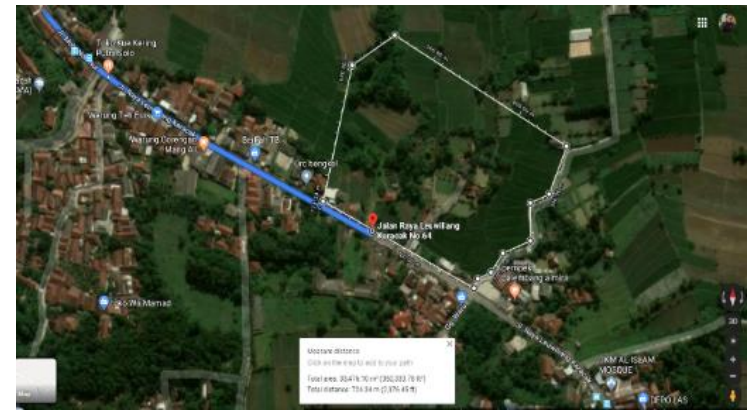

Gambar 1 Lokasi Tapak

\section{DATA TAPAK SECARA DETAIL}
a. Provinsi
: Jawa Barat
b. Wilayah
: Kabupaten Bogor
c. Kecamatan
: Leuwiliang
d. Desa
: Barengkok
e. Luas Tapak
: $33.246 \mathrm{~m} 2$
f. Tata Guna
: Pp2 Zona Kawasan
Lahan
g. Batas Tapak
Utara
Pemukiman Perkotaan
(Hunian Sedang)
Timur : Lahan Pertanian Warga
Selatan : Jl.Kracak Leuwiliang
Barat : Perumahan warga

\section{TATA GUNA LAHAN}

Berdasarkan PERDA No.11 Tahun 2016 tentang RTRW Kabupaten bogor 2016 - 2036, tata guna lahan dimana lokasi tapak perancangan merupakan zona sebagai berikut :
a. Peruntuka
Pp2
Zona
Kawawan

Pemukiman (Hunian Sedang)

b. Luias Lahan : $33.246 \mathrm{~m} 2(3,32 \mathrm{Ha})$

c. Peraturan : $\mathrm{KDB}=50 \%-60 \%$

$\mathrm{KLB}=4$

$\mathrm{RTH}=30 \%$

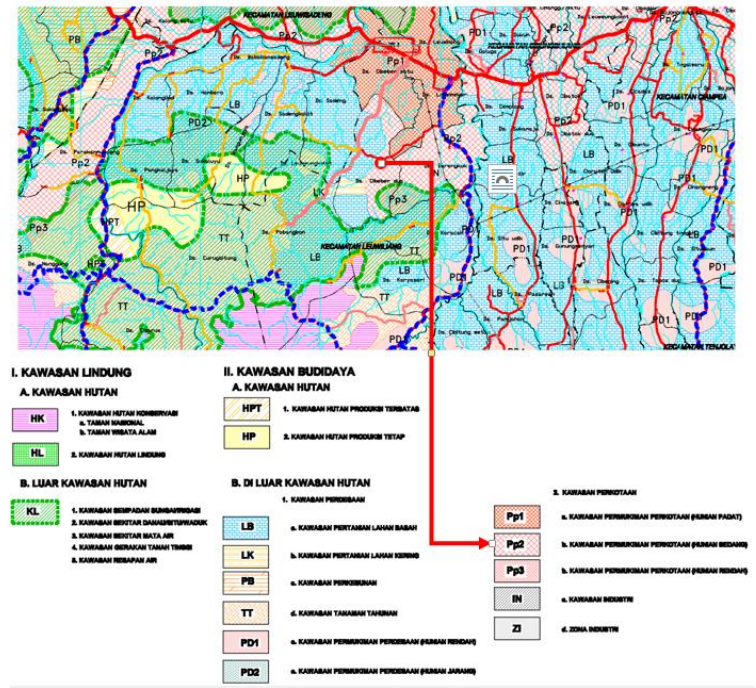

Gambar 2 Peta Tata Guna Lahan

Table 2 Tabel Ketentuan Umum Peraturan Zonasi

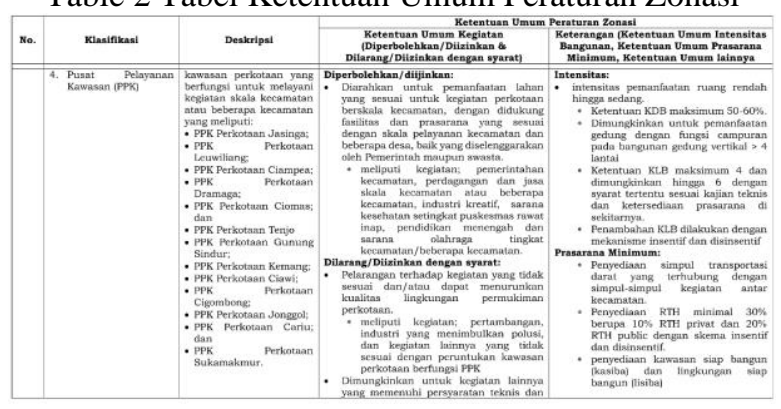

\section{HASIL ANALISA TAPAK}

Berdasarkan proses analisa tapak meliputi : analisa tapak, analisa view, konfigurasi tapak, analisa pencapaian, analisa iklim, penzoningan dan analisa terhadap peraturan bangunan :

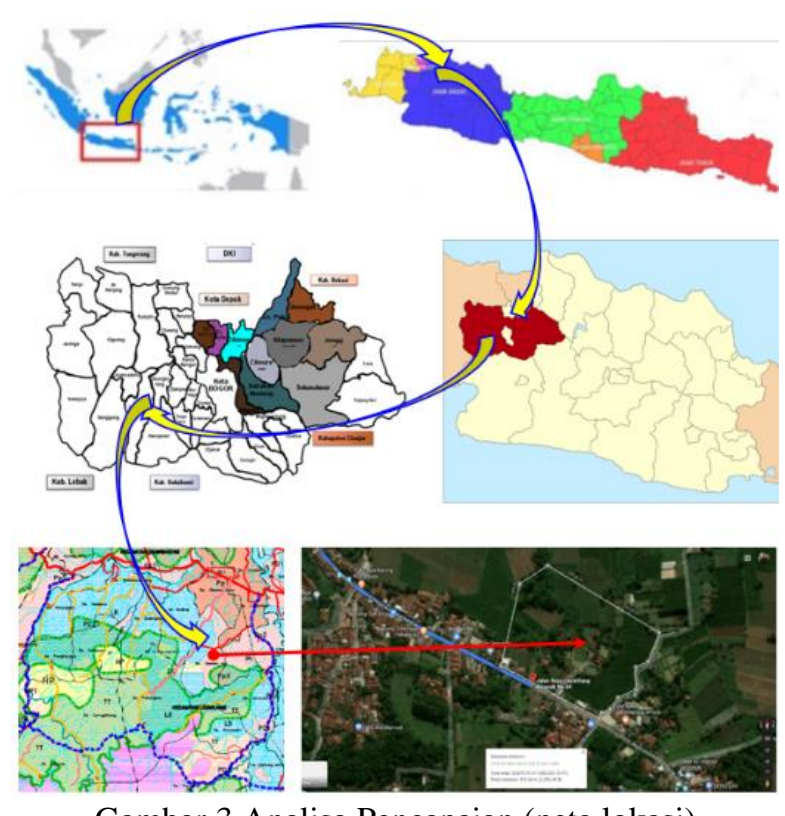

Gambar 3 Analisa Pencapaian (peta lokasi) 

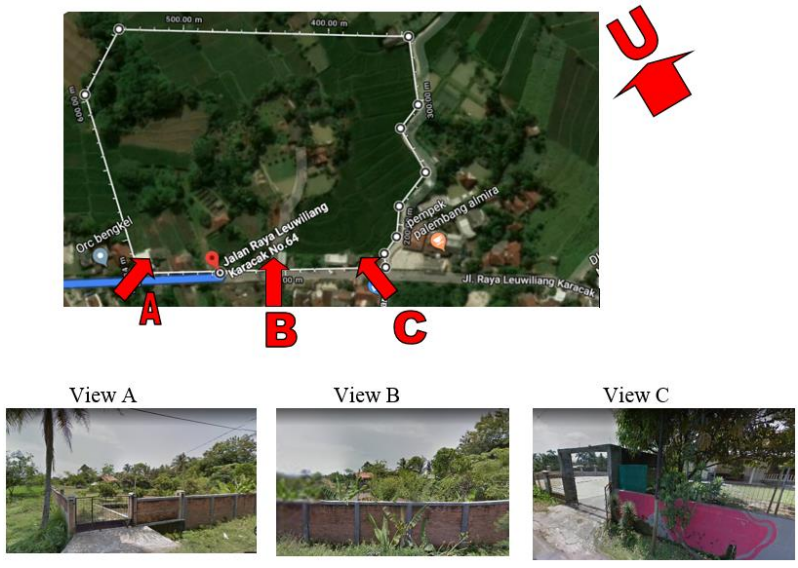

Gambar 4 Foto kondisi eksisting tapak

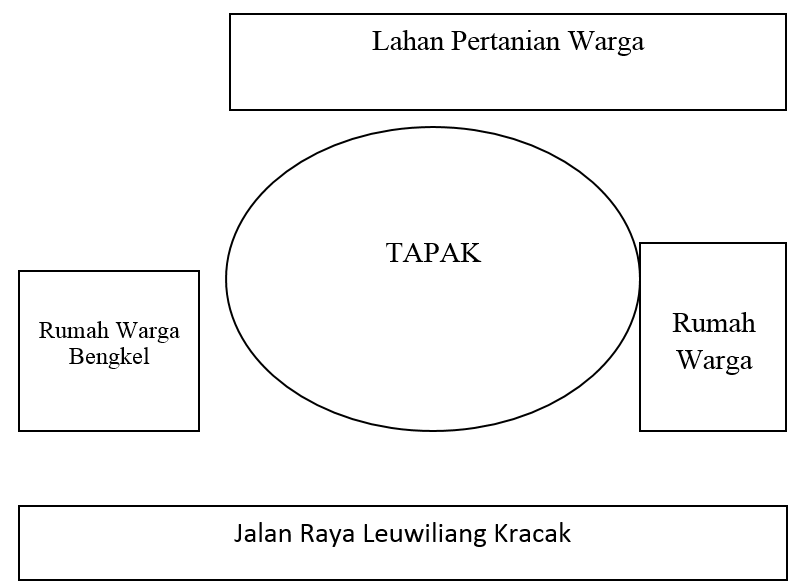

Gambar 5 Analisa konfigurasi tapak

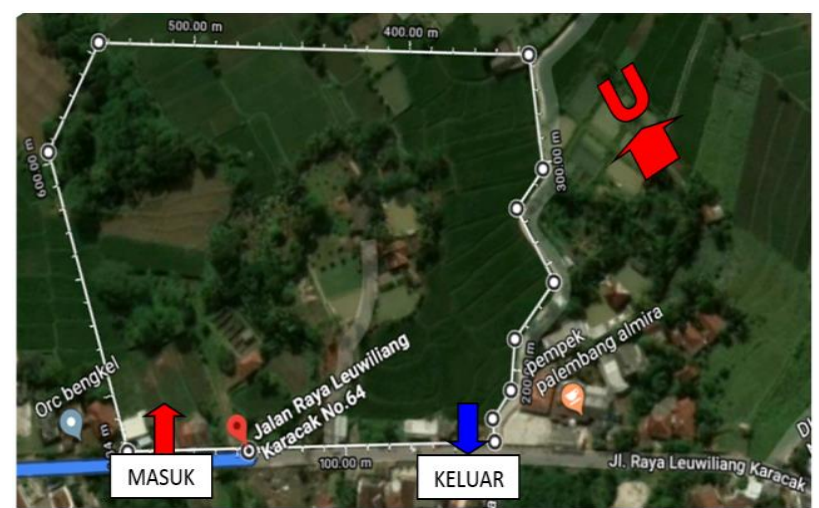

Gambar 6 Analisa gerbang masuk dan keluar

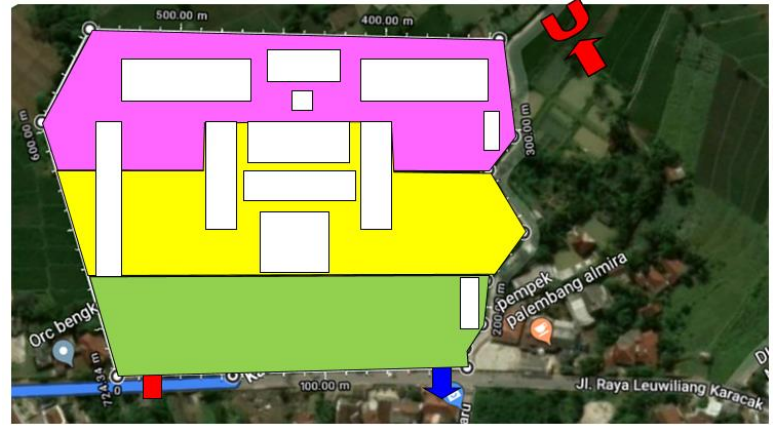

Gambar IV.6: Penzoningan

Area Publik

$\square$ Area Semi private

$\square$ Area private

Gambar 7 Zonasi area public, semi privat dan privat

\section{KONSEP TAPAK}

Berdasarkan hasil analisa tapak dan konsep sirkulasi dinamis maka diperoleh konsep tapak sebagai berikut .

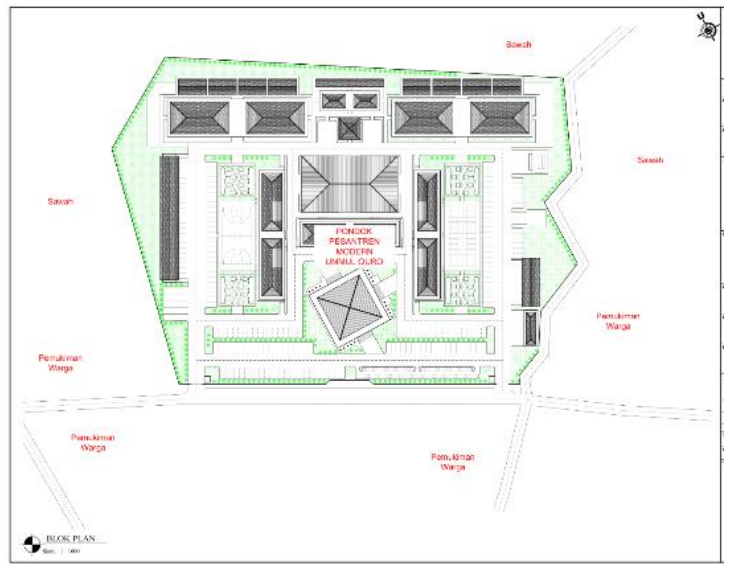

Gambar 8 Konsep Tapak

Table 3 Tabel Luas Bangunan

\begin{tabular}{|c|c|c|c|c|c|c|}
\hline \multirow{2}{*}{ No } & \multirow{2}{*}{ Nama Gedung } & \multicolumn{2}{|c|}{ Ukuran $(\mathrm{m})$} & \multirow{2}{*}{$\begin{array}{l}\text { Luas Tapak } \\
\text { (m2) }\end{array}$} & \multirow{2}{*}{$\begin{array}{l}\text { Jml. } \\
\text { Lantai }\end{array}$} & \multirow{2}{*}{$\begin{array}{l}\text { Luas Bangunan } \\
\text { (m2) }\end{array}$} \\
\hline & & Panjang & Lebar & & & \\
\hline A1 & Gedung Kelas Mts & 64 & 12.5 & 800 & 3 & 2,400 \\
\hline A2 & Gedung Kelas Alliyah & 64 & 12.5 & 800 & 3 & 2,400 \\
\hline A3 & Gedung Kantor Guru \& Lab & 49 & 12.5 & 612.5 & 3 & 1,838 \\
\hline B & Aula Serbaguna & 45 & 25 & 1125 & 1 & 1,125 \\
\hline c & Kantin & 45 & 25 & 1125 & 1 & 1,125 \\
\hline D & Mesjid & 30 & 30 & 900 & 2 & 1,800 \\
\hline E & Asrama Tsanawiayah & 70 & 19 & 1330 & 3 & 3,990 \\
\hline $\mathrm{F}$ & Asrama Alliyah & 70 & 19 & 1330 & 3 & 3,990 \\
\hline G & Asrama Ustadzah & 30 & 10 & 300 & 3 & 900 \\
\hline $\mathrm{H}$ & Rumah Kyai & 9 & 9 & 81 & 2 & 162 \\
\hline 1 & Wisma & 60 & 7 & 420 & 3 & 1,260 \\
\hline 1 & Dapur & 12 & 8 & 96 & 2 & 192 \\
\hline $\mathrm{K}$ & UQ Mart \& Book Store & 18 & 7 & 126 & 1 & 126 \\
\hline L & Area Jajanan & 22.5 & 3 & 67.5 & 1 & 68 \\
\hline & & & LUAS & 9,113 & & 21,375 \\
\hline
\end{tabular}

Luas Tapak Bangunan $9.118 \mathrm{~m} 2=27,4 \%$ dari Luas Lahan, hal tersebut tidak melebihi KDB yang telah ditentukan sebesar 50\% $60 \%$ dari lluas lahan. 


\section{PENZONINGAN}

Berdasarkan analisa tapak yang telah dilakukan, dan penerapan konsep dinamis diperoleh gambar penzoningan sebagai berikut.

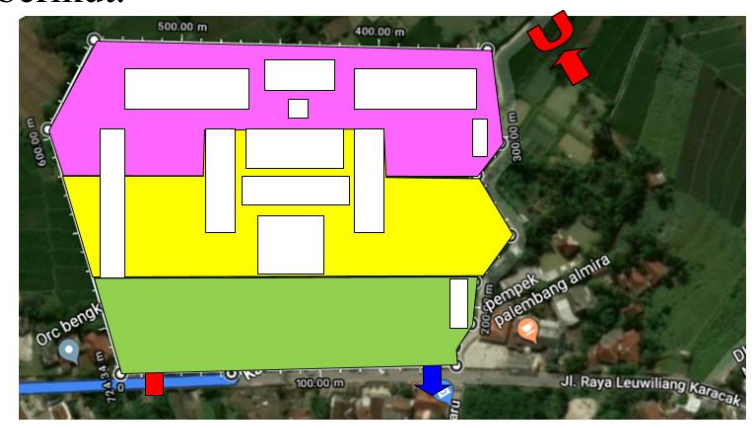

Gambar IV.6: Penzoningan

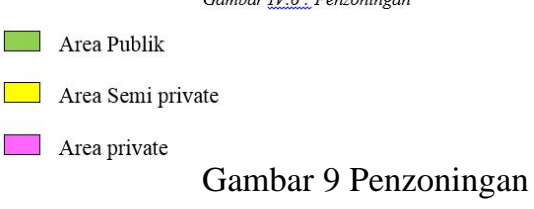

\section{TRANSFORMASI BENTUK}

Berdasarkan sejarah singkat Pondok Pesantren Ummul Quro nama Ummul Quro sendiri diambil dari julukan kota Mekkah di Saudi Arabia Maksud pendiri mengambil nama ini adalah untuk tabarrukan (mengambil keberkahan) dari kota suci Mekkah yang selalu dibanjiri oleh kaum Muslimin dari segala penjuru dunia.

Kota Mekkah dimana Masjidil Haram berada, dalam menyusunan massa bangunan pada tapak penulis menerapkan tipologi bangunan yang ada di Masjidil Haram.

Ka'bah sebagai pusat dan kiblat seluruh umat Islam di seluruh dunia. Dalam lingkup yang lebih kecil yaitu lingkup pesantren dan masyarakat sekitar, dimana masjid sebagai pusat kegiatan pendidikan di pesantren ditempatkan di tengah komplek pesantren dan memungkinkan sirkulasi dinamis yang sangat efisien dan efektif menjadikan Mesjid mudah dijangkau oleh semua pihak khususnya dari segala penjuru komplek pesantren dan masyarakat umum yang dikhususkan untuk majlis ta'lim perempuan binaan pondok dari lingkungan sekitar.

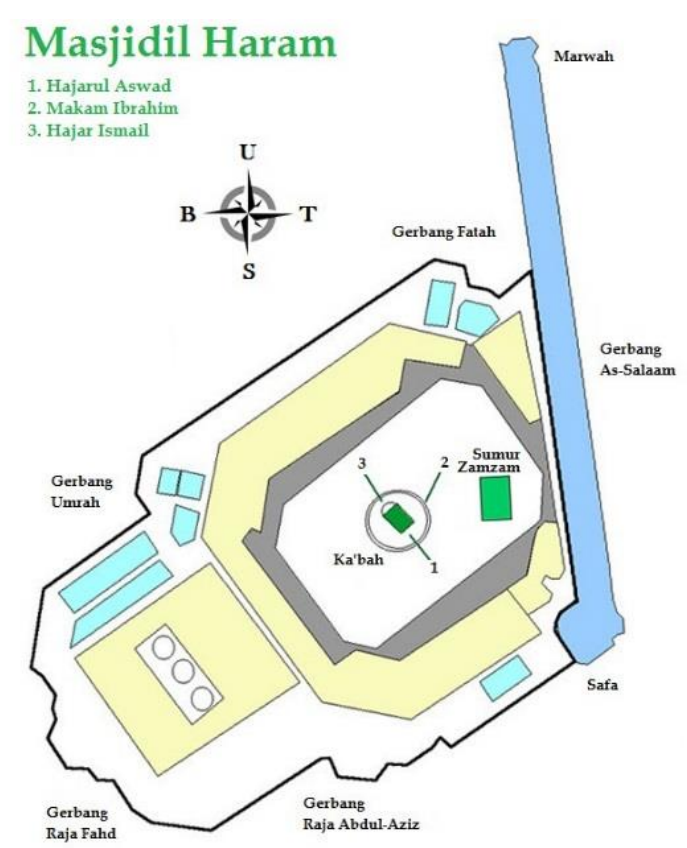

Gambar 10 Tipologi Masjidil Haram
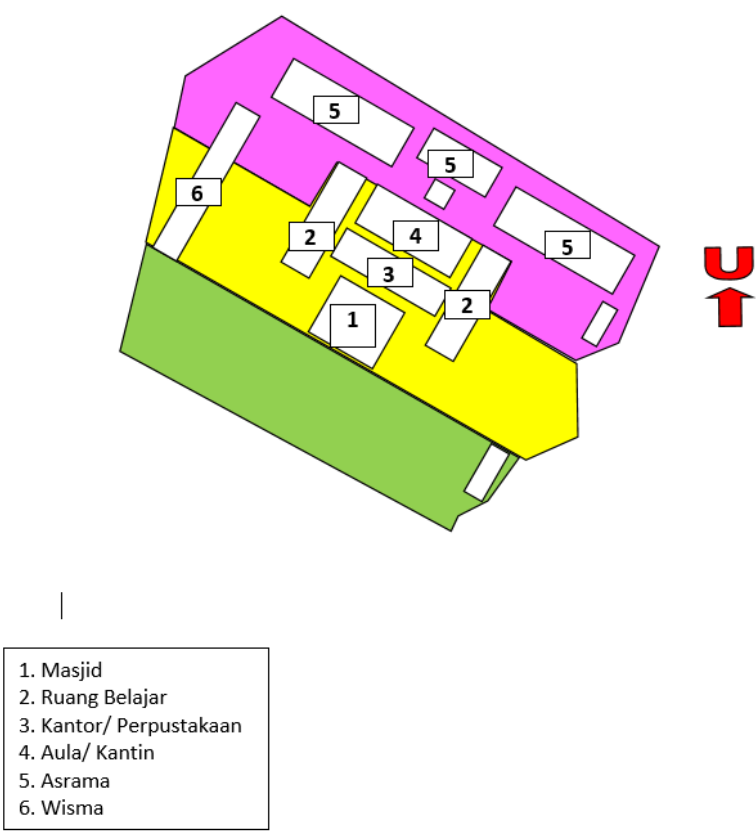

Gambar 11 Tipologi Pondok Pesantren Modern Ummul Quro 
110 Perancangan Pondok Pesantren Modern Ummul Quro di Kabupaten Bogor

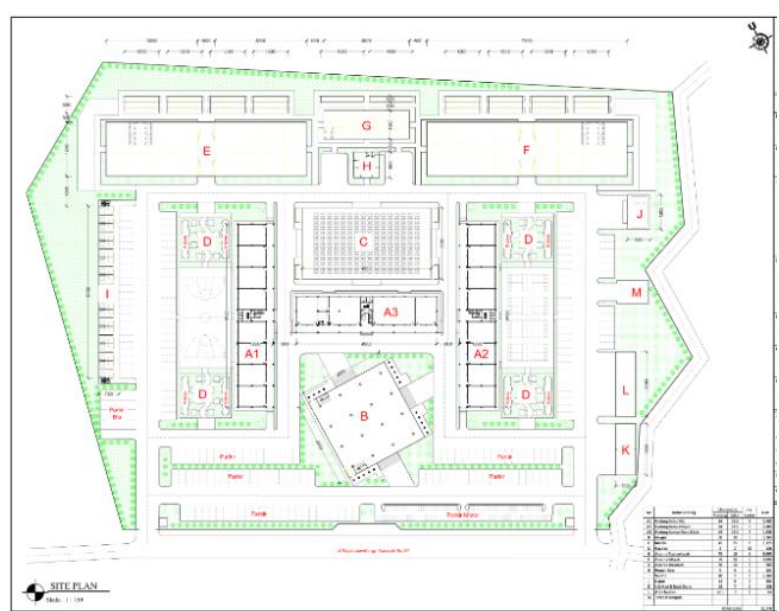

Gambar 12 Site Plan

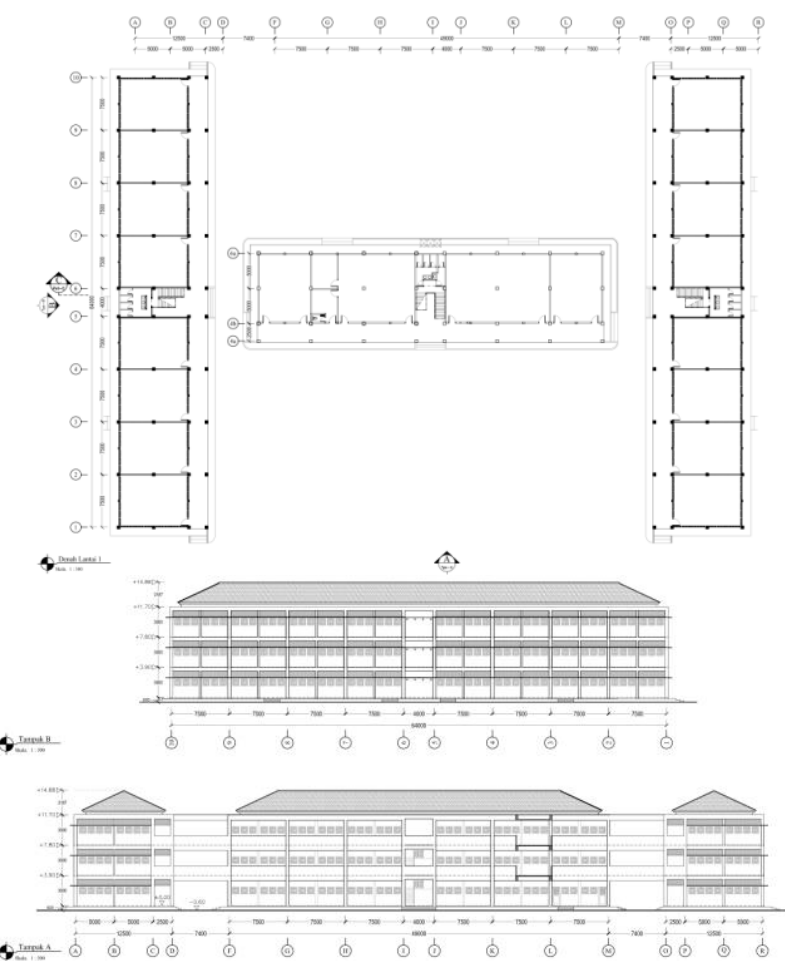

Gambar 13 Denah \& Tampak Ruang Kelas
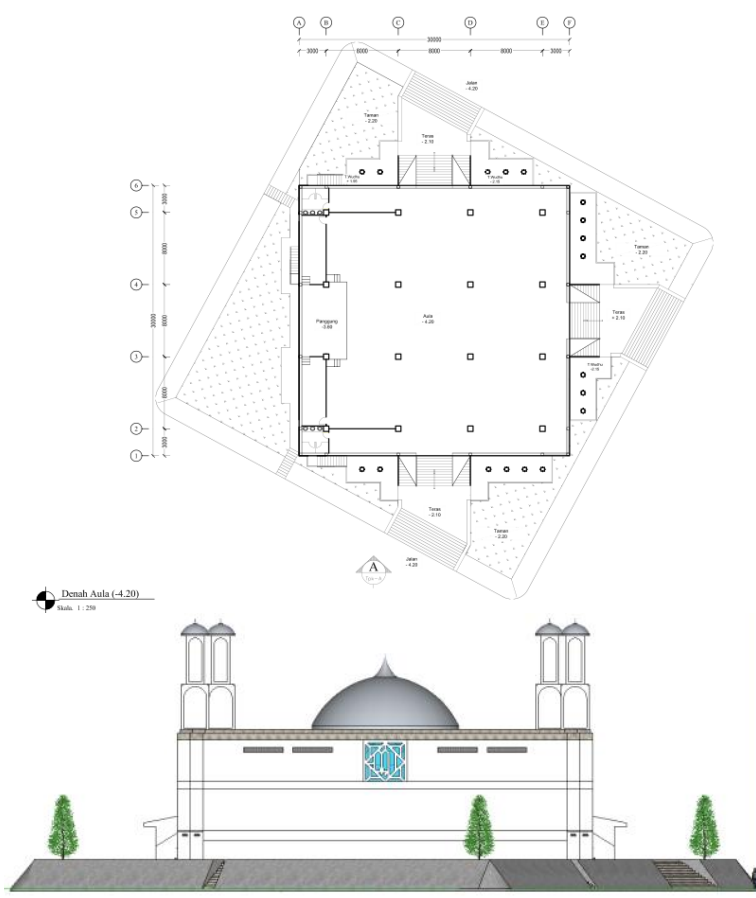

Gambar 14 Denah \& Tampak Aula dan Mesjid
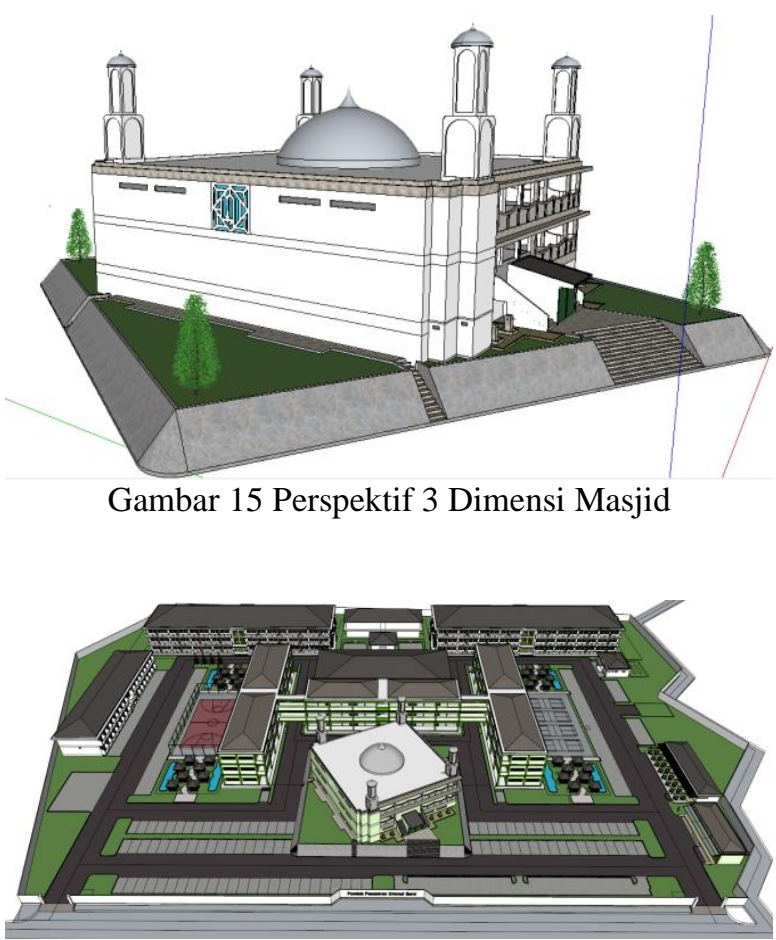

Gambar 16 Perspektif 3 Dimensi Tapak

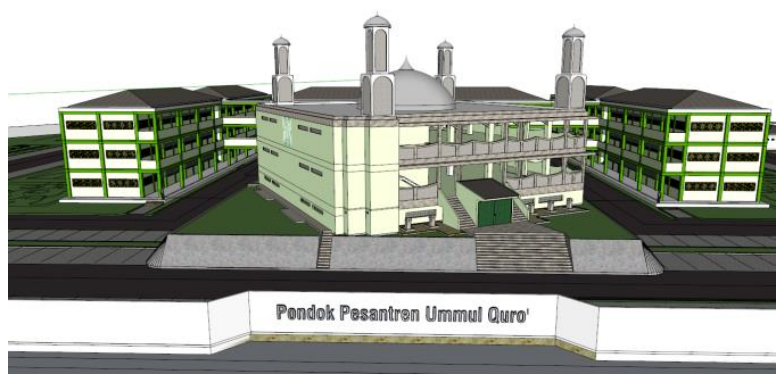

Gambar 17 Perspektif 3 Dimensi Bagian depan 


\section{PENUTUP}

\section{Simpulan}

Pendidikan merupakan faktor yang sangat penting dalam rangka membina generasi penerus Bangsa yang memiliki akhlak mulia dan budi pekerti yang luhur berlandaskan keimanan dan ketaqwaan kepada Allah SWT.

Pondok pesantren hadir ditengah masyarakat memberikan solusi sebagai alternatif pendidikan dalam menghadapi pesatnya kemajuan dari sisi sosial, budaya untuk mendidik generasi penerus Bangsa.

Dari hasil perancangan Pondok Pesantren Modern Ummul Quro di Kabupaten Bogor dapat disimpulkan bahwa :

1. Perancangan secara sistematis yang bertujuan untuk menciptakan lingkungan pondok pesantren yang nyaman bagi para santri dan guru khususnya dan bagi para pengunjung umumnya.

2. Perancangan yang dilakukan dengan memperhatikan kaidah-kaidah arsitektur sehingga diperoleh penataan bangunan dan ruang secara efektif dan efisien dari segi tata letak bangunan, optimalisasi lahan dan kebutuhan pengguna.

\section{Saran}

Setelah melakukan perancangan Pondok Pesantren Modern Ummul Quro di Kabupaten Bogor berdasarkan studi kasus di beberapa pondok pesantren, adabeberapa saran yang ingin penulis sampaikan berkaitan dengan Pondok Pesantren Modern :

1. Dalam mendirikan pondok pesantren modern perlu direncanakan secara matang dengan memperhatikan aspek-aspek kebutuhan ruang, sirkulasi dan kenyamanan, meskipun dalam pembangunannya dilakukan secara bertahap.

2. Dengan hadirnya Pondok pesantren sebagai lembaga pendidikan yang mandiri berbasis masyarakat dengan mengedepankan pendidikan akhlaq, budi pekerti luhur dan moral berlandaskan iman dan taqwa sesuai dengan tutunan Al-Qur'an dan Sunah, diharapkan melahirkan generasi penerus Bangsa yang dapat memajukan Bangsa dan mendapat Ridho Alloh SWT.

\section{DAFTAR PUSTAKA}

Sumaryoto, Pedoman Penulisan Skripsi / Tugas Akhir. Jakarta: Universitas Indraprasta PGRI.

Kamus Besar Bahasa Indonesia Online, kbbi.kemdikbud.go.id

Qomar, muzammil. Pesantren : Dari Transformasi Metodologi Menuju Demokratisasi Institusi.

Dhofier, Zamakhsyari. Tradisi pesantren : Studi Tentang Pandangan Hidup Kyai.

Tanggoro, Dwi. 2006 Struktur Bangunan Tinggi dan Bentang Lebar. Jakarta : Universitas Indonesia.

Tanggoro, Dwi. 2006 Utilitas Bangunan. Jakarta : Universitas Indonesia.

Tjahjadi, Sunarto. 1996. Data Arsitek Jilid 1. Jakarta: Erlangga

Sumalyo, Yulianto. Arsitektur Modern Akhir Abad XIX dan Abad XX Edisi ke-2.

Lingkup pekerjaan arsitek, Tahapan Kerja Arsitek, https://iai-jakarta.org 